\title{
Reduction in sucrose reward magnitude without generalization decrement
}

\author{
R. A. BURNS and D. P. BURNS \\ Georgia Southwestern College, Americus, Georgia 31709
}

\begin{abstract}
Groups of albino rats were trained for 24 days in a straight runway with one of two different liquid sucrose concentrations, $30 \%$ or $3 \%$, as reward. Training trials were administered $2 /$ day with an intertrial interval (ITI) of 3-5 min. This preshift phase was followed by an additional 24 days in which both groups received the $3 \%$ solution. A significant main effect of reward magnitude developed early in the preshift phase and persisted throughout the postshift phase. Since the number of daily trials and the ITI employed in this experiment have been shown in other designs to be optimal for the conditioning of the sensory consequences of responding with sucrose rewards, the data argue against a generalization decrement account of the successive contrast effect.
\end{abstract}

A pair of recent experiments on sequences of sucrose reward (Burns, 1976) suggests that the conditioning of the traces (aftereffects) of sucrose rewards is most readily accomplished when only two daily training trials are employed with an intertrial interval (ITI) of 3-5 min. In the first experiment, rats given two-trial sequences of large and small liquid sucrose rewards (SL and LS) patterned their responses, running fast on large-reward trials and slow on small-reward trials, and showed ordered resistance to extinction; the rats given the daily sequence LS were less resistant to extinction than the group given SL. Each of these findings suggested the influence of the conditioned sensory consequences of responding, aftereffect learning (Capaldi, 1967; Leonard, 1969). No such evidence of aftereffect learning was present in a second experiment in which an alternating sequence of large and small sucrose rewards was administered 10 trials/day with an ITI of $60 \mathrm{sec}$. The notion that sucrose rewards produce strong and longlasting aftereffects was suggested as a possible reason for the disparate results of these two experiments. The strong trace of sucrose rewards should be optimally effective when only 2 trials/day are given, but with more within-days trials, particularly with shorter ITIs, sucrose becomes less effective because it compounds the interference from the outcomes of preceding trials.

The successive negative contrast effect (SuNCE) often occurs in rats when reward magnitude is reduced. It appears as a disruption in the performance of a downshifted group relative to unshifted controls (Crespi, 1942; Elliott, 1928). One popular notion is that SuNCEs are the result of generalization decrement (Capaldi \& Lynch, 1967). The sensory consequences of reward

This research was supported by the Charles L. Mix Memorial Fund through the Department of Psychology at Georgia Southwestern College. Requests for reprints should be sent to R. A. Burns, Department of Psychology, Georgia Southwestern College, Americus, Georgia 31709. on Trial $\mathrm{N}-1$ are assumed to become conditioned to the instrumental response by reward on Trial N. Since each reward magnitude is assumed to produce specific aftereffects, changes in the magnitude of reward should alter the stimulus complex, reducing effective habit strength by generalization decrement. There are conditions, however, under which the SuNCE does not occur, and one of these is when different concentrations of sucrose instead of different numbers of food pellets are used as reward (Flaherty, Riley, \& Spear, 1973; Homzie \& Ross, 1962; Rosen, 1966; Rosen \& Ison, 1965; Shanab, France, \& Young, 1975). Instances in which SuNCEs do not occur may involve ineffective conditioning of aftereffects to the instrumental response. This notion has been expressed in a variety of forms (Capaldi, 1967; Flaherty et al., 1973; Likely, Little, \& Mackintosh, 1971; Mackintosh, 1974), each of which goes little further than to suggest that somehow sucrose aftereffects are nondifferentiable.

The experiments on sequence of sucrose reward suggest, however, that these sucrose traces are clearly differentiable when administered under favorable conditions: namely, 2 trials/day with a 3 - to 5-min ITI. These conditions not only produced differential rates of extinction in varied reward groups, they also produced an inverse relation between the amount of consistent sucrose reward and resistance to extinction, a phenomenon analogous to the SuNCE (Gonzalez \& Bitterman, 1969) and expected on the basis of generalization decrement. Other experiments examining sucrose reward magnitude effects on extinction have, conversely, failed to obtain the interaction (Ison \& Rosen, 1968; Likely et al., 1971).

Since none of the experiments that failed to produce the SuNCE with sucrose rewards, whether reward reduction was to a lower concentration or to extinction, have employed what are apparently optimal parameters for sucrose aftereffect learning, the present experiment 
was conducted to examine the feasibility of the generalization-decrement account of SuNCE. Sucrose concentration was reduced from $30 \%$ to $3 \%$ after a group of rats was trained to traverse a runway 2 trials/day for 24 days. The intertrial interval was 3-5 min. If generalization decrement is a major factor in the SuNCE, then reduction in sucrose concentration under these optimal conditions for aftereffect learning should produce contrast where similar reductions under different conditions have failed.

\section{METHOD}

\section{Subjects}

The subjects were 14 experimentally naive Dublin SpragueDawley rats approximately 90 days old at the beginning of preliminary training. The rats were obtained from Flow Laboratories, Dublin, Virginia.

\section{Apparatus}

The apparatus, described fully elsewhere (Burns, 1976), was a wooden runway (182.9 cm long) with a hinged, clear Plexiglas cover. The startbox and alley were painted black. The goalbox was painted white and positioned at a 90-deg angle. Start and retrace doors were manually operated and recording of start and run times was accomplished with photocell logic to two Standard Electric timers.

\section{Preliminary Training}

Animals were housed in individual cages in the room in which the experiment was conducted. During the first 3 days of preliminary training, all animals were allowed free access to food and water and were placed on a walled exercise table for $15 \mathrm{~min}$ each day, then weighed. On Day 4 systematic reduction to $85 \%$ of free-feeding body weight (based on the average weight during the 3 preceding days) was begun. On Day 7 animals were randomly assigned to one of two groups and allowed $15-\mathrm{min}$ free access to either $30 \%$ sucrose solution or $3 \%$ sucrose solution delivered on the table. The sucrose was mixed by percentage weight in tap water and delivered in the removable goal cup, which was fashioned from a teaspoon. Table feeding continued until Day 10. All animals were then randomly assigned to one of four squads, each consisting of three or four rats, and goalbox placements, which entailed placing each rat in the goalbox containing $1 \mathrm{ml}$ of sucrose, were administered twice a day on Days 11-17. During the entire experiment, the order of running of squads and rats within squads was randomly determined each day, and for goalbox and preshift training, the concentration of sucrose for each rat was the same as that employed during table feeding.

\section{Preshift Training}

There were 24 preshift days, two trials each day. A trial began with the opening of the start door $3 \mathrm{sec}$ after the rat was placed in the startbox. When the animal entered the goalbox, the retrace door was closed, and the rat was removed after the reward ( $1 \mathrm{ml}$ of $30 \%$ or $3 \%$ sucrose) was consumed. Throughout the experiment, subjects were run in rotation within a squad to maintain an ITI of 3-5 min. Subjects spent the ITI in the living cage with water available. Following an exercise period of approximately $15 \mathrm{~min}$ after each daily running, each rat was weighed and fed its calculated ration in the home cage.

\section{Postshift Training}

During the 24 days of postshift training, all experimental conditions remained the same except that the rats who had received $30 \%$ sucrose throughout the preshift training received an equal volume of $3 \%$ sucrose instead.

\section{RESULTS}

All raw time scores were transformed $[10 \times \ln (x+1)]$ and separate analyses were performed for the pre- and postshift stages on both start and run measures (each of which yielded fundamentally identical results). A clear and rapid discrimination of reward magnitude was demonstrated during the 24 days of preshift training. The main effect of groups $[F(1,12)=27.54, p<.01]$ and the interaction of Groups by Days $[F(5,60)=5.30$, $\mathrm{p}<.01$ ] were both significant. Animals tended to run faster on the second daily trial than on the first $[F(1,12)=10.43, p<.01]$ in both groups $(F<1)$.

The performance of these rats during the 24 days in which the reward magnitude remained the same for the $3 \%$ group but was reduced to $3 \%$ in the group previously trained with $30 \%$ is shown in two-trial blocks in Figure 1. The first two points in this figure (unconnected) are the run times on the last day of preshift. There is no hint of anything similar to the SuNCE. In fact, the overall effect of groups remained significant $[F(1,12)=7.99$, $\mathrm{p}<.05$ ] in spite of the reward reduction. A slight decrease, evidenced by the interaction of Groups by Days $[F(5,60)=2.81, p<.05]$, in run times for the shifted group did occur, but it was gradual and incomplete.

\section{DISCUSSION}

This experiment produced an unmistakable result, a gradual and almost trivial decline in the run times of rats following a large reduction in the amount of sucrose reward. The point to be made by this result seems clear. There is reason to think, on the basis of previous experiments on sequence of sucrose reward, that the conditions of this experiment, not only the number of daily trials and the ITI, but the equipment, method of deprivation, preliminary training procedures, and so on, were

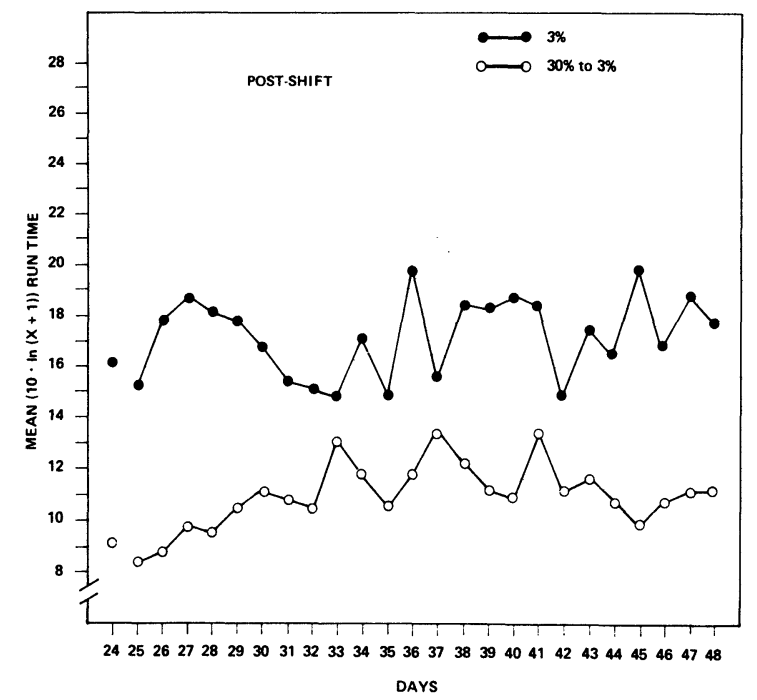

Figure 1. Mean transformed run times during postshift. The first two points (unconnected) are the means for the last day of preshift. The remaining points represent means for the two daily trials. 
such as to insure conditioning of the aftereffects of sucrose reward magnitudes. To the extent that aftereffect learning is the predecessor to generalization decrement when reward magnitudes are changed, the postulated mechanism of the SuNCE (Capaldi, 1967; Capaldi \& Lynch, 1967), the results of the present experiment suggest that generalization decrement is not the mechanism of successive contrast.

Of course, generalization decrement is also not the only mechanism of contrast that has been proposed. The effect, in fact, has been at the base of a major theoretical debate since 1928 , concerning the role of reward in instrumental learning (cf. Black, 1968; Dunham, 1968), and the importance of this issue underscores the importance of meaningful analysis of the proposed mechanisms.

Criticism of the generalization-decrement account of successive contrast has taken two forms, one old and well represented and the other new and underexplored. The first criticism is that while conditioned sensory traces may disrupt performance through generalization decrement in massed trials, there is no good evidence that these traces are durable enough to span long (e.g., 24-h) ITIs (e.g., Gonzalez \& Bitterman, 1969). A sizable number of demonstrations of the SuNCE have been with $24-h$ ITIs, and recent work by Capaldi $(1971,1972)$ has centered on hypothetical memory mechanisms, as opposed to sensory traces, that may bridge the ITI in spaced trials. The second, and perhaps more promising, form of criticism comes from analysis of those situations that do not produce the SuNCE. Reward reduction in goldfish has consistently failed to produce successive contrast (Gonzalez, Ferry, \& Powers, 1974; Gonzalez, Potts, Pitcoff, \& Bitterman, 1972; Lowes \& Bitterman, 1967; Mackintosh, 1971). Gonzalez et al. (1974) reviewed a variety of sources of evidence that suggest that goldfish are capable of learning the sensory consequences of responding under optimal conditions; fish show patterning, for example, in single alternation of reward and nonreward if the trials are highly massed and training is extensive. Although no fish contrast experiments have been conducted under identical conditions to those reported by Gonzalez et al. (1972) to be effective for aftereffect learning in fish, the reasonable inference drawn from the fish comparisons was that it is doubtful that generalization decrement is the mechanism of successive contrast.

The present experiments with sucrose rewards fall nicely into the second category of criticism, and, because the identical conditions that produced aftereffect learning in a design other than the contrast design failed to produce the SuNCE here, it offers a stronger argument. Although strongly suggestive, it is not, however, a sufficient argument for dismissal of the notion as it stands. Consider the possibility, for example, that sucrose rewards interfere with the effects of generalization decrement in some way other than through the initial conditioning of aftereffects. Such a possibility is suggested by the fact that an inverse relation between the amount of consistent reward and resistance to extinction was obtained in the sucrose sequence experiment (Burns, 1976). That contrast was produced (under ideal conditions) by a shift to extinction but not by a shift to a smaller value of sucrose suggests that sucrose may have some motivational properties that counteract generalization effects, that perhaps sucrose rewards should not be viewed on a continuum with nonrewards as can other types of reward (Capaldi \& Lunch, 1967), or that some other possibility exists that, like the others, warrants investigation.

\section{REFERENCES}

BLACK, R. W. Shifts in magnitude of reward and contrast effects in instrumental and selective learning: A reinterpretation. Psychological Review, 1968, 75, 114-126.

Burns. R. A. Effects of sequences of sucrose reward magnitudes with short ITIs in rats. Animal Learning \& Behavior, 1976, 4. 473-479.
Capaldi, E. J. A sequential hypothesis of instrumental learning. In K. W. Spence \& J. T. Spence (Eds.), The psychology of learning and motivation (Vol. 1). New York: Academic Press, 1967.

CAPaldi, E. J. Memory and learning: A sequential viewpoint. In W. K. Honig \& P. H. R. James (Eds.), Animal memory. New York: Academic Press, 1971.

CAPAldI, E. J. Successive negative contrast effect: Intertrial interval, type of shift, and four sources of generalization decrement. Journal of Experimental Psychology, 1972, 96, 433-438.

CAPAldi, E. J., \& Lynch, A. D. Repeated shifts in reward magnitude: Evidence in favor of an associational and absolute (noncontextual) interpretation. Journal of Experimental Psychology, 1967, 75, 226-235.

CRESPI, L. P. Quantitative variation of incentive performance in the white rat. American Journal of Psychology, 1942, 55, 467-517.

Dunham, P. J. Contrasted conditions of reinforcement: A selective critique. Psychological Bulletin, 1968, 69, 295-315.

ElliotT, M. H. The effect of change of reward on the maze performance of rats. University of California Publications in Psychology, 1928, 4, 19-30.

Flaherty, C. F., Riley, E. P., \& Spear, N. E. Effects of sucrose concentration and goal units on runway behavior in the rat. Learning and Motivation, 1973, 4, 163-175.

Gonzalez, R. C., \& Bitterman, M. E. Spaced-trials partial reinforcement as a function of contrast. Journal of Comparative and Physiological Psychology, 1969, 67, 94-103.

Gonzalez, R. C., Ferry, M., \& Powers, A. S. The adjustment of goldfish to reduction in magnitude of reward in massed trials. Animal Learning \& Behavior, 1974, 2, 23-26.

Gonzalez, R. C., Potts, A., Pitcoff, K., \& Bitterman, M. E. Runway performance of goldfish as a function of complete and incomplete reduction in amount of reward. Psychonomic Science, 1972, 27, 305-307.

Homzie, M. J., \& Ross, L. E. Runway performance following a reduction in the concentration of a liquid reward. Journal of Comparative and Physiological Psychology, 1962, 55, 1029-1033.

Ison, J. R., \& Rosen, A. J. Extinction and reacquisition performance as a function of sucrose-solution rewards and number of acquisition trials. Psychological Reports, 1968, 22, 375-379.

LEONARD, D. W. Amount and sequence of reward in partial and continuous reinforcement. Journal of Comparative and Physiological Psychology, 1969, 67, 204-211.

Likely, D., Little, L., \& Mackintosh, N. J. Extinction as a function of magnitude and percentage of food or sucrose reward. Canadian Journal of Psychology Review of Canadian Psychology, 1971, 25, 130-137.

Lowes, G., \& Bitterman, M. E. Reward and learning in the goldfish. Science, 1967, 157, 455-457.

Mackintosh, N. J. Reward and aftereffects of reward in the learning of goldfish. Journal of Comparative and Physiological Psychology, 1971, 76, 225-232.

Mackintosh, N. J. The psychology of animal learning. New York: Academic Press, 1974.

Rosen, A. J. Incentive-shift performance as a function of magnitude and number of sucrose rewards. Journal of Comparative and Physiological Psychology, 1966, 62, 487-490.

Rosen, A. J., \& Ison, J. R. Runway performance following changes in sucrose rewards. Psychonomic Science, 1965, 2, 335-336.

Shanab, M. E., France, J., \& Young, T. Negative contrast effect obtained with downshifts in magnitude but not concentration of solid sucrose reward. Bulletin of the Psychonomic Society, 1975, 5, 429-432.

(Received for publication May 30, 1978.) 